\title{
Socioeconomic inequalities in health and the use of healthcare services in Catalonia: analysis of the individual data of 7.5 million residents
}

Guillem Lopez-Casasnovas (Center for Research on Health and Economics (CRES), Universitat Pompeu Fabra \& Barcelona Graduate School of Economics (BGSE))

\section{Key Words}

Socioeconomic related health inequalities, economic crisis, Catalan Health System, evidencebased health policies

\section{Introduction}

Social protection systems are related to each community's culture. In most of the developed countries with welfare systems health care provides universal access to their population. Despite its achievements, the main concern today of public health systems is financial sustainability. The challenge results from the fact that most of the health systems are very set in their ways and do not seem much prepared to answer that is to come in health care. And as our cause of concern here, for the interventions likely to be required to fight against the inequity that will result from those future developments. This forces to rethink our systems and to direct universalism to a greater extent towards the most needy, fragile population that have been left behind by the economic crisis and may suffer loss of access to some innovations in health care.

This is particularly the case of the Spanish system. This does not seem prepared to prioritize services and set proper population targets to show resilience to the consequences of future technological and economic changes. In Catalonia, a rather wealthy region in Spain (see Garcia-Altés et al in this issue), despite rather good health outcomes for a reasonable health care expenditure, in terms of equality, the gap in socioeconomic inequalities has already increased during the last decades, firstly by immigration, driven by the economic boom, followed by unemployment caused by the economic crisis. They have generated new vulnerable groups (unemployees, children and elderly). In addition some proposals from the former Spanish conservative government to change the terms of access to universal health services to pursue fiscal deficit control (1) may lead things to worse.

The economic consequences of the past crisis overlap with problems related to technological innovation and pressures on utilization of the health system, emerging further issues on equity. We know that in order to face them, the old universalism of the welfare states, a free for all, is not an all-purpose solution (2). In terms of equity, universalism must be understood as a complete and potential eligible access for all citizens. But this should not exclude the filter to give priority to those in higher relative need and/or lack of means. We cannot ignore moreover the fact that equal access does not guarantee equality in consumption or in health results. The opportunity costs of access to health care open up gaps (self-employed, illegal immigrants, functional illiterates, those with handicaps and physical limitations, etc.) which are mainly linked to socioeconomic factors. The greater the awareness through knowledge or contacts of how the system works, associated with the high socioeconomic status, the more utilization of public facilities is made by high income groups, causing health care expenditure to reduce its public redistributive capacity. At the same time, the past crisis may have created a sense, or allow people to notice a weakening of public services (perceived quality, waiting times). A lack of confidence with the future of the Spanish health system has emerged. The ESADE Index [3] shows that trust in the system has been damaged in spite of economic recovery and increasing expenditure

In this new context, it becomes very relevant to identify and adapt our health system to the emerging challenges and build on them evidence based responses. For this purpose we can 
now take advantage of what we can learn about the equity gaps and the mechanisms related to socioeconomic inequalities in Catalonia (see Garcia-Altés et al's paper).

The 2017 Catalan Report on Inequalities in Health Care is a milestone. So far existing studies in Spain had focused on aggregate data, disregarding specific subgroups of the population, or on information from individual surveys, with substantial methodological shortcomings and a risk of biased comparisons [4]. On top of this, there is scarce knowledge about the actual mechanisms that relate socioeconomic and health inequalities, and the existing mediating factors. Therefore, many health policy proposals tend to be based on intuitions or ideology, instead of evidence.

In 2013, the Government of Catalonia agreed already to closely monitor the determinants of health as well as the health status of the population, in order to assess the impact of the economic crisis and to examine some related issues. Now the 2017 Report analyses individual data of the entire population of Catalonia (7.5 million inhabitants). It refers information regarding their income level and financial benefits provided by the Social Security system and it relates to information about their health, their use of public healthcare services and drug consumption, focusing specifically on vulnerable groups [5]. The Catalan Health System Observatory may then examine inequalities in health, the utilization of public healthcare services and drug consumption among the population of Catalonia, according to socioeconomic levels that take both the employment status of the person as well as their income level into account. These are stratified by sex and age, and it allows identify specifically those more vulnerable groups.

\section{What does the Catalan evidence tell us?}

Both across Catalonia and Spain, indicators such as life expectancy or general mortality do not appear in the short time to have been directly affected by the economic crisis $[6,7]$, although there is some evidence of the effect of the crisis on health factors, changes in certain lifestyles and access to health services. In some cases already points to an increase in mortality (5) all due to causes related to unemployment. However, by focusing solely on average population rather than on the most disadvantaged one, the study of health inequalities is not sufficient. Results show that there is in fact a socioeconomic gradient in all indicators analysed in the Report, both in health and in the utilization of healthcare services, in the consumption of drugs and in most combinations of age and sex cohorts. This gradient is small in primary and emergency care, being greater in drug consumption (particularly antipsychotics) and much higher in mental healthcare services and hospital care (especially psychiatric and avoidable hospitalizations). There is also an important gradient in mortality. The mortality rate shows a remarkable social gradient in people under the age of 65 . All of these results have been concluded with respect to the standardization mentioned in the Report. Therefore it requires greater care not only in interpreting the predicted effects but also in applying the intervention mechanisms for the future correction. Undoubtedly, we need to avoid making exaggerated interpretations of the upshots because marking incremental ratios do not distinguish base values in absolute terms.

Although the gap between social groups is reduced as age increases, a higher percentage of the population of pensioners with lower incomes are in situations of high complexity compared to higher income groups. Children's health depends, as expected, on the socioeconomic level of their parents. This effect is greater on an intergenerational level, due to the dynamics of social mobility, than on an intragenerational one at a given moment of time. For that reason, cross-section analysis often lead to simplistic interpretations of the increases in health inequality that result in misguided policy recommendations; policymakers implement complex policies that are less effective than just ending the "austericide" 
(austerity in public spending). Furthermore, despite extensive evidence on those generational consequences, it does not seem that the dynastic element is well taken by the health authorities. In order to do so, we would need to focalize policies rather than simply demanding "more resources for health;" a demand that is often embedded in the claim against inequality in a very indiscriminate way.

Morbidity, the use of mental healthcare centres, hospitalization rates and the probability of consuming drugs in girls and boys of a lower socioeconomic level is 3 to 5 times higher than those with a higher socioeconomic status, and up to seven times in the case of psychiatric hospitalization. However, an additional clarification is required here because without intending to detract from the importance this subject deserves, the number of people affected is in fact very small, particularly psychiatric hospitalization.

In addition to socioeconomic inequalities, consistently observed in all indicators, the 2017 Report shows also marked differences between women and men both in healthcare service utilization and consumption of drugs, as well as in health outcomes, and this seems to be the case for all age groups and almost all socioeconomic levels analysed. It is evident, therefore, how gender inequalities are perpetuated throughout people's life cycle and affect those of all socioeconomic levels.

\section{Building evidence-based policies to tackle socioeconomic health-related inequalities}

Despite limitations to extracting common results [8], the most affected area to be prioritized is that of mental health, since suicides tend to increase with social fragility. Another group of the population deserving of special attention is infancy. This category shows a structural representation of inequalities. When parents are living in adverse socioeconomic conditions, these have a direct impact on the health and development of their children, and on top of this, these problems at such a young age will have a negative effect in the long term both on their health and on their socioeconomic level [9]. They tend indeed to be influenced by their parents' socioeconomic conditions which become difficult to leave behind.

There is increasing scientific evidence [10] both in biology and social sciences that points to the importance of the first years of life -including in utero exposure- in the formation of the capacities that promote well-being through the life cycle. Inequality in early childhood is an important cause of inequalities in the skills provided by social development (educational achievements, health and behavioral hazards, income levels, etc.). If no measures are introduced to change the course of their lives, children who grow up disadvantaged are at risk on a socioeconomic and a biological level for the rest of their lives. Moreover, the risk of illness increases more rapidly with age among disadvantaged populations.

Women generally have worse health states than men: they suffer from more illnesses or chronic health problems, as well as more anxiety problems and depression, disabilities or permanent limitations. Studies on health inequalities according to gender have traditionally been performed parallel to studies on socioeconomic levels, but it is very important to bear in mind that both of these axes of inequality act simultaneously.

There are studies to suggest that the association between inequalities in health and socioeconomic level is not linear, but follows a curve showing that inequalities are more pronounced up to the approximately $€ 30,000$ per year bracket, after which the effects smooth out [11]. These results indicate that those policies aimed at eradicating situations of poverty, which lead to a reduction in the number of people living in precarious conditions, result in major benefits in terms of health. In the case of the Catalan Report mentioned here, belonging to category corresponding to an income bracket of $€ 18,000$ or more leads to a significant improvement in health indicators.

\section{Concluding comment}


In brief, the study of Garcia-Altés et al shows that despite the fact that the Catalan Health Care Service is a universal and well developed system, there still exist significant socioeconomic inequalities in health and use of healthcare services in the population of Catalonia. Disparities in the utilization of public healthcare services are not necessarily considered bad if health inequalities exist, and these variations occur to some extent in response to the differences in citizens' states of health. It is more worrying however to see differences in mortality according to socioeconomic levels than no differences in the use of healthcare services. Since it is not possible to fully adjust resources to the degree of each person's needs, we cannot fully ascertain whether the gradient observed in the use of services is the appropriated one. The Catalan Report highlights the need to respond to this situation through more fine-tuned health analysis and correspondingly, tailor-made public policies grounded on education and labour.

The experience shows that in order to reduce the steepness of the social gradient in health, actions must be universal, but with a scale and intensity that is proportionate to the level of disadvantage (this is proportionate universalism [12]. In addition national policies do not work without effective local delivery systems working on three main principles of health justice: better cost-effectiveness, non-discrimination and priority to the worse off in terms of both current severity of illness and a lifetime health perspective.

\section{REFERENCES}

1. Juanmarti, A. López-Casasnovas, G. Vall Castelló, J. "The deadly effects of losing health insurance" CRESWP\#201804-104 2018 [Download]

2. Abásolo, I.; Saez, M.; López-Casasnovas, G. Financial crisis and income-related inequalities in the universal provision of a public service: the case of healthcare in Spain. Int. J. Equity Health 2017, 16: 134.

3. López-Casanovas, G in ESADE Encuesta de valores sociales. CaixaBank: Barcelona, Spain, 2017.

4. López-Casanovas, G; Maynou, L; Saez, M. Another look at the comparisons of the health systems expenditure indicators. Social Indicators Research 2015, 121, 149-175.

5. Observatori del Sistema de Salut de Catalunya. Desigualtats socioeconòmiques en la salut i la utilització de serveis sanitaris públics de la població de Catalunya. Observatori sobre els efectes de la crisi en la salut de la població. Agència de Qualitat i Avaluació Sanitàries de Catalunya. Departament de Salut. Generalitat de Catalunya: Barcelona, Spain, 2017. Available online: http://observatorisalut.gencat.cat/web/.content/minisite/observatorisalut/ossc crisi salut/Fitxers crisi/Salut crisi informe 2016.pdf (accessed on 6 October 2017)

6. Lopez Bernal, J.A.; Gasparrini, A.; Artundo, C.M.; McKee, M. The effect of the late 2000s financial crisis on suicides in Spain: an interrupted time-series analysis. Eur. J. Public Health 2013, 23, 732-736.

7. Librero J.; Segura, A.; González López-Varcárcel, B. Suicides, hurricanes and economic crisis. Eur. J. Public Health 2014, 24, 183.

8. OECD. Health at a Glance 2015: OECD Indicators. OECD Publishing: Paris, France, 2015. Available online: http://dx.doi.org/10.1787/health glance-2015-en (accessed on 6 October 2017)

9. Fjær, E.L.; Balaj, M.; Stornes, P.; Todd, A.; McNamara, C.L.; Eikemo, T.A. Exploring the differences in general practitioner and health care specialist utilization according to education, occupation, income and social networks across Europe: findings from the European social survey $(2014)$ special module on the social determinants of health. Eur. J. Public Health 2017, 27, 73-81. 
10. Goldblatt, P.; Siegrist, J.; Lundberg, O.; Marinetti, C.; Farrer, L.; Costongs, C. Improving health equity through action across the life course: Summary of evidence and recommendations from the DRIVERS project. (Report produced as part of the 'DRIVERS for Health Equity' project). EuroHealthNet: Brussels, Belgium, 2015. Available online:

11. Costa-Font, J.; Hernández-Quevedo, C.; Sato, A. A Health 'Kuznets' Curve'? CrossSectional and Longitudinal Evidence on Concentration Indices. Soc Indic Res 2017. DOI: $10.1007 / \mathrm{s} 11205-017-1558-8$.

12. Fair Society, Healthy Lives. The Marmot Review. Strategic Review of Health Inequalities in England post-2010. UCL Institute of Health Equity: London, United Kingdom, 2010. 